Article

\title{
Comparing Winds near Tropical Oceanic Precipitation Systems with and without Lightning
}

\author{
Timothy J. Lang (D)
}

NASA Marshall Space Flight Center, Huntsville, AL 35812, USA; timothy.j.lang@nasa.gov; Tel.: +1-256-961-7861

Received: 13 November 2020; Accepted: 2 December 2020; Published: 4 December 2020

check for updates

\begin{abstract}
In order to examine how robust updraft strength and ice-based microphysical processes aloft in storms may affect convective outflows near the surface, ocean winds were compared between tropical maritime precipitation systems with and without lightning. The analysis focused on Cyclone Global Navigation Satellite System (CYGNSS) specular point tracks, using straightforward spatiotemporal matching criteria to pair CYGNSS-measured wind speeds with satellite-based precipitation observations, Advanced Scatterometer (ASCAT) wind speeds, and lightning flash data from ground-based and space-based sensors. Based on the results, thunderstorms over the tropical oceans are associated with significantly heavier rain rates ( $200 \%$ greater $)$ than non-thunderstorms. However, wind speeds near either type of precipitation system do not differ much $\left(\sim 0.5 \mathrm{~m} \mathrm{~s}^{-1}\right.$ or less). Moreover, the sign of the difference depends on the wind instrument used, with CYGNSS suggesting non-thunderstorm winds are slightly stronger, while ASCAT suggests the opposite. These observed wind differences are likely related to lingering uncertainties between CYGNSS and ASCAT measurements in precipitation. However, both CYGNSS and ASCAT observe winds near precipitation (whether lightning-producing or not) to be stronger than background winds by at least $1 \mathrm{~m} \mathrm{~s}^{-1}$.
\end{abstract}

Keywords: CYGNSS; ASCAT; ISS LIS; GLM; WWLLN; winds; precipitation; lightning; convection

\section{Introduction}

A common feature of near-surface winds near convection is a short-term ( $\sim 30 \mathrm{~min}$ or less) increase in average wind speed, often coupled with a shift in dominant wind direction. This is caused by evaporatively cooled air within the storm that descends to the surface and then spreads out laterally, and is commonly referred to as a gust front [1]. Behind the gust front, the air is often cooler than the environment. This region is referred to as a cold pool [2-4]. In addition to modulating the evolution of the convection responsible for their genesis, cold pools and their associated gust fronts also play important roles in the initiation and development of new convection [2].

There are important questions regarding how gust front genesis relates to the kinematic and microphysical structure and evolution of convection. For example, there is significant uncertainty about the strength of gust fronts that are produced in convection that is characterized by relatively weaker updrafts and has its precipitation primarily produced by warm-rain microphysical processes, versus gust fronts produced in convection that has relatively stronger updrafts and relatively more of its precipitation produced by ice-based microphysical processes [5]. In the latter case, the precipitation system would be expected to produce lightning, since lightning is the result of charge separation caused by rebounding collisions between ice hydrometeors in the presence of supercooled liquid water [6]. Indeed, many studies have demonstrated that lightning is quantitatively correlated to ice water content, updraft strength, and vertical fluxes of ice hydrometeors [7-10].

Relative to unelectrified convection, electrified storms typically are larger in area, and contain stronger updrafts, larger ice water paths (IWP), and are vertically deeper [9-13]. Thus, it is reasonable 
to expect that thunderstorms should feature stronger gust fronts compared to storms without lightning. In addition, as lightning flash rate increases, this tends to signal intensification of the convection, to the point that very high flash rate storms are likely to be associated with severe weather, such as damaging winds from intense gust fronts [14,15]. However, due to the relative sparseness of global wind observations, it is difficult to demonstrate this hypothesis conclusively, let alone quantify the actual differences observed between gust fronts associated with thunderstorms and gust fronts associated with storms without lightning.

Over oceans, scatterometers such as the Advanced Scatterometer (ASCAT) are capable of retrieving near-surface vector winds, but these measurements are more uncertain in precipitation [16-18]. The Cyclone Global Navigation Satellite System (CYGNSS) uses Global Positioning System (GPS) reflectometry to retrieve wind speed over the oceans [19]. Because it is L-band, CYGNSS is expected to be less impacted by precipitation, and its ability to retrieve accurate winds in rain has been demonstrated [20]. CYGNSS provides coverage of oceanic winds in the global tropics.

Due to its ability to accurately retrieve winds even in the presence of heavy rain [20], which is common near tropical convection, CYGNSS was chosen as the basis for this study. By combining CYGNSS observations with global precipitation measurements, as well as global/regional lightning datasets, this study will quantify differences in winds near lightning-producing oceanic convection versus convection without lightning. In turn, this study will attempt to determine (in a categorical sense) the impact of relatively stronger updrafts and ice microphysical processes on wind speeds near precipitation systems, as thus by proxy infer potential impacts on cold pool and gust front strength.

\section{Materials and Methods}

\subsection{CYGNSS}

The CYGNSS constellation of 8 small satellites provides observations of wind speeds over the tropical and subtropical oceans between approximately $\pm 38^{\circ}$ latitude. This study used version 2.1 CYGNSS Level 2 wind data [21]. Version 2.1 data have been validated to meet all CYGNSS level 1 science requirements [20]. However, observations formed by signals from Block IIF GPS satellites are excluded from version 2.1 due to calibration uncertainties. This reduces the available number of wind observations by roughly one third.

CYGNSS wind retrievals are available for specular reflections of GPS signals, and tracks are formed by a series of reflections corresponding to a single GPS satellite and one of the antennas on a single CYGNSS observatory. As noted by [19,22], a single track of specular reflections comprises a fundamental and physically consistent grouping of CYGNSS observations. Therefore, this study's analysis focus was on CYGNSS tracks, and other datasets (e.g., ASCAT, IMERG, lightning) were matched to CYGNSS at the track level.

Version 2.1 Level 2 CYGNSS wind files do not organize CYGNSS observations by track. However, tracks can be identified and grouped via organizing CYGNSS winds by contributing antenna, observatory number, and GPS satellite number (pseudorandom noise or PRN code). However, on a given day there can be multiple tracks with these common values. Therefore, the DBSCAN (Density-Based Spatial Clustering of Applications with Noise) [23] clustering algorithm was applied to these common groups to further decompose to individual tracks. The track-separation algorithm allowed up to $1^{\circ}$ difference in latitude/longitude and a time gap of $60 \mathrm{~s}$ before a new track was identified from a set of common antenna, observatory, and PRN numbers. The software used to create these tracks was the open source Python Interface to CYGNSS Wind Dataset (PyGNSS) [24].

Each track-including geolocation and timing information, range-corrected gain (RCG), and wind speeds from the Fully Developed Seas (FDS) and Young Seas Limited Fetch (YSLF) retrieval algorithms - was saved to an individual Network Common Data Format (netCDF) file. YSLF wind speeds are generally only valid near tropical cyclones, while FDS wind speeds are accurate in other circumstances [20]. However, it remains useful to study the utility of YSLF winds near more 
conventional tropical precipitation, so this study analyzed both types of retrievals. Note that the dataset included tropical cyclones, but since these are rare (relative to conventional tropical precipitation systems) they likely did not impact overall results significantly.

Tracks were identified for May 2017 through December 2019. With the full constellation operational, typically 2000-3000 tracks are available per day, and each track can contain an average of 200-300 wind observations over a time period lasting several minutes. CYGNSS samples along an individual track at $1 \mathrm{~Hz}$ [20], so based on orbit speed the average spacing along a track is $6 \mathrm{~km}$. This provides roughly 4:1 oversampling relative to the nominal CYGNSS resolution of $25 \mathrm{~km}$. However, data gaps often occur, but, as mentioned previously, the track identification algorithm described above allows for that.

\subsection{ASCAT}

ASCAT is a C-band scatterometer that measures ocean vector winds. ASCAT consists of a dual-fan-beam radar, which measures along two parallel swaths. Currently, there are three ASCAT instruments in orbit onboard the Meteorlogical Operational (Metop) A, B, and C satellites. The time period of May 2017 through December 2019 was analyzed, so this study only focused on ASCAT-A and -B. For each of these instruments, the $12.5-\mathrm{km}$ coastal-optimized Level 2 data $[25,26]$ were analyzed. Because this study was focused primarily on CYGNSS, only the ASCAT wind speed measurements were used, not wind direction. ASCAT is included in this study in order to examine the sensitivtiy of the results to the choice of wind instrument.

ASCAT winds were matched to CYGNSS tracks in the following way. All CYGNSS tracks that overlapped the time period of a particular ASCAT orbit (approximately $90 \mathrm{~min}$ ) were examined for that granule. The closest-in-distance ASCAT wind speed observation from either swath was matched to each CYGNSS specular reflection along a track; however, any ASCAT wind measurement more than $20 \mathrm{~km}$ away from the track was excluded, even if it was the closest. Only about 25\% of CYGNSS tracks have matchups from either ASCAT-A or -B, because the CYGNSS track and ASCAT swaths often did not overlap spatially within the $\sim 90$-min orbit window. Moreover, typically any overlap occurred only during a portion of the CYGNSS track's length. In sum, the number of matched samples with ASCAT was $<10 \%$ of the entire track-based dataset. Matched ASCAT winds were included as a new field in each CYGNSS track file.

\subsection{IMERG}

IMERG (Integrated Multi-satellitE Retrievals for GPM) is a global precipitation dataset produced as part of the GPM (Global Precipitation Measurement) mission [27]. Precipitation rates are retrieved using intercalibrated passive microwave measurements from a constellation of satellite radiometers in low-Earth orbit (LEO). Geostationary infrared (IR) measurements are used to morph and advect the precipitation in a physically consistent way between LEO passive microwave overpasses.

IMERG data are available every half hour on a global $0.1^{\circ}$ grid. Each CYGNSS track was matched to the temporally closest IMERG file (with the caveat that the IMERG time could not be later than the midpoint time of the track), and then the precipitation at the nearest neighbor IMERG gridpoint was matched to each specular reflection within the CYGNSS track. Due to the timing of when the track-based processing occurred, CYGNSS track files prior to 2019 were matched to the version 5 Late IMERG products, while 2019 data were matched to version 6 Final IMERG products. Based on a sensitivity analysis using a subset of data (not shown), these version differences did not significantly impact any of this study's results.

\subsection{Lightning}

\subsubsection{WWLLN}

The Worldwide Lightning Location Network (WWLLN) is a ground-based network that detects radio-frequency $(\mathrm{RF})$ emissions from lightning on a global basis [28]. The network is most sensitive to 
powerful cloud-to-ground (CG) flashes, and thus only detects a small fraction of total lightning [29]. However, it does enable continuous monitoring of thunderstorms over the global oceans, and thus is a useful dataset for comparison with satellite observations of oceanic winds. For this study, the only data used were from 1 August through 31 October of 2018 and 2019 (6 months of data), as they were obtained in support of field campaigns that operated during those periods [30]. However, because of the continuous global observations, this short time period still provided the most matchups of lightning flashes with the CYGNSS tracks, of the three lightning datasets examined in this study.

WWLLN data were matched to CYGNSS tracks in the following manner. Only lightning occurring during a given track's duration (typically several minutes) was considered. Contiguous portions of the track with nonzero IMERG precipitation were automatically identified, and if lightning was identified within $25 \mathrm{~km}$ of a specular point in the raining portion of a track, that wind measurement was included in the "winds with lightning" category. The flash rate related to that wind measurement was calculated by totaling all flashes within $25 \mathrm{~km}$ of the specular point, and dividing by the duration of the track itself. To limit cross-contamination, matching lightning anywhere along a track led to the exclusion of that track from contributing to the "winds without lightning" category (even if the track featured some raining areas without lightning). For tracks that had no lightning within $25 \mathrm{~km}$ anywhere along it, but did have raining portions, winds within the raining portion were added to the "winds without lightning" category. Typically $<10 \%$ of the overall raining dataset featured lightning.

The advantage of using WWLLN is that the dataset is global and the temporal coverage is continuous. The disadvantage is that it does not detect all lightning, and thus many wind regions without lightning may in fact be near thunderstorms with undetected lightning. This will tend to cause some overlap between winds associated with lightning, and those without. Figure 1 shows the analysis region for WWLLN, which includes all of the CYGNSS sampling region.

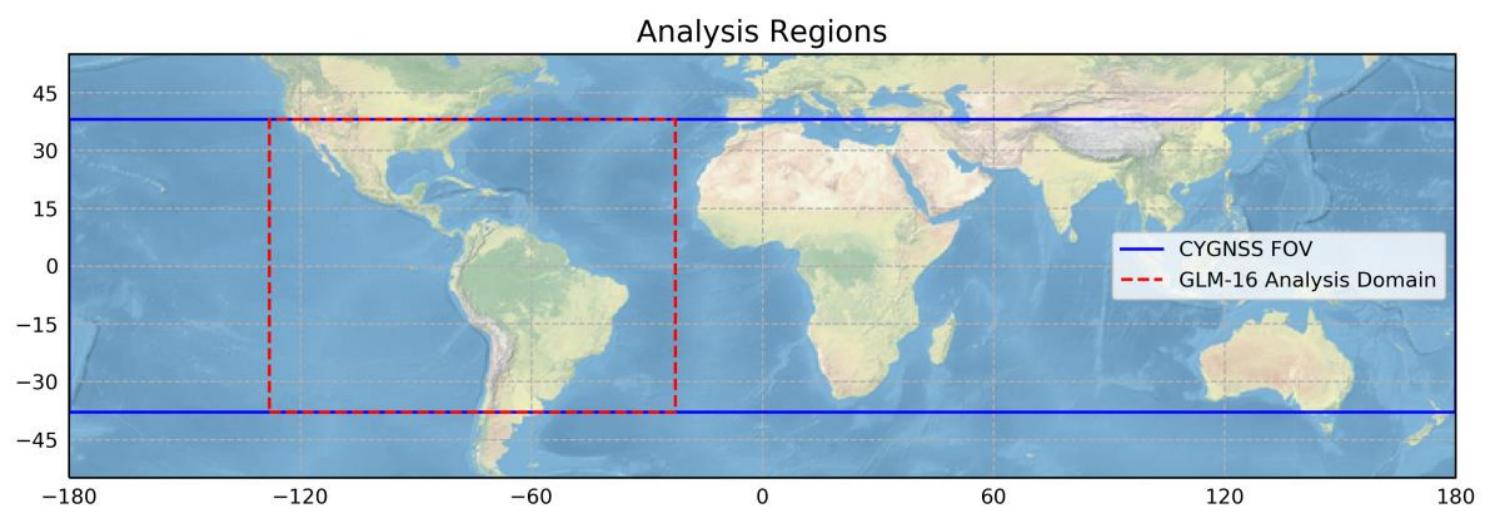

Figure 1. Analysis regions for this study. The observed map is the ISS LIS field of view (FOV), and WWLLN observes the full domain as well. The blue box shows the CYGNSS FOV. The dashed red box is the domain used for GLM analysis in this study. Land regions have no valid CYGNSS winds.

\subsubsection{GLM}

Observations from the Geostationary Lightning Mapper (GLM) on the Geostationary Operational Environmental Satellite (GOES) 16 were also used. GLM-16 continuously monitors a hemispheric field of view (FOV) centered on $75.2^{\circ} \mathrm{W}$, which encompasses North and South America (landmasses where CYGNSS does not provide wind observations), the eastern Pacific Ocean, the western Atlantic Ocean, as well as the Gulf of Mexico and the Caribbean Sea. GLM detects total lightning with a detection efficiency of approximately $70 \%$, and its instantaneous field of view (IFOV) varies between 8-14 km depending on viewing angle [31,32]. Six months from each of 2018 and 2019 (1 July through 31 December), for a total of 12 months of observations, were included in this study.

As noted by [31,32], the GLM-16 FOV varies as a function of latitude. Thus, to ensure continuous monitoring, only CYGNSS tracks occurring (or overlapping) within the box marked by $\pm 38^{\circ}$ latitude, and 128 to $22.5^{\circ} \mathrm{W}$ longitude, were considered when comparing to GLM-16 (Figure 1). This ensured 
that these tracks were always within the GLM-16 FOV regardless of latitude. Because of the continuous FOV, GLM-16 lightning was matched to CYGNSS tracks in a similar manner to WWLLN. However, coordinates for flash centroids were used as the basis of comparison. GLM-16 group and event data were ignored in this study.

The advantage of using GLM-16 is that it provides continuous coverage of total lightning, with high detection efficiency. The disadvantage is that the dataset is not global, and thus a longer analysis period was required to obtain a comparable number of samples to the WWLLN dataset, despite the higher lightning detection efficiency. The reason GLM-16 was used in this study was to confirm whether trends observed by the CG-focused WWLLN analysis were also observed when using a total lightning dataset.

\subsubsection{ISS LIS}

The International Space Station Lightning Imaging Sensor (ISS LIS) is the modified flight spare of the original Tropical Rainfall Measuring Mission (TRMM) LIS [33,34]. This instrument has been in orbit on the ISS since early 2017, and provides routine monitoring of lightning between $\pm 55^{\circ}$ latitude. ISS LIS has a detection efficiency of $\sim 60 \%$, and a location accuracy better than its $4-\mathrm{km}$ IFOV [33]. All months of version 1 ISS LIS data from May 2017 through December 2019 were analyzed in this study (32 total months) [35].

Because ISS LIS is a LEO instrument, it does not provide a continuous FOV, and thus instrument viewing time needs to be considered. Lightning matchups were considered differently compared to WWLLN and GLM-16, for which viewing time was not a constraint. Similar to the ASCAT matchup approach, only CYGNSS tracks that intersected the ISS LIS swath during a particular orbit were considered. The ISS LIS swath was defined as the portion of the FOV where viewing time was at least $60 \mathrm{~s}$. ISS LIS viewing time for a given location on the ground is nominally close to 90 s [36], but can be reduced near swath edge, during ISS orbital maneuvers, or when the ISS solar panels pass through the FOV. This viewing time filter thus removes the most obscured portions of the orbit from consideration, although it may potentially cause low-flash-rate storms to appear as having no lightning. Once the properly observed swath was defined, matchups with CYGNSS tracks proceeded similarly to GLM-16, which has a very similar data structure. Only flash centroids, and not groups or events, were considered.

The advantage of ISS LIS is that it provides global coverage (Figure 1) of total lightning with high detection efficiency. The disadvantage is that it does not provide continuous coverage of a particular region. Thus, the number of samples is greatly reduced compared to WWLLN and even GLM-16, despite a significantly longer dataset. The reason ISS LIS was used was to enable a longer sampling period that included additional seasons (namely, January-July), and to confirm whether trends observed using the regional total lightning provided by GLM-16 also manifested globally.

\subsection{Synthesis}

The synthesized CYGNSS track dataset provided matchups with ASCAT-A and -B within approximately $\pm 90 \mathrm{~min}$ (the duration of one Metop orbit), IMERG within $30 \mathrm{~min}$, and three different complementary lightning measurements within the duration of the track itself (typically several minutes). In addition, the analysis was structured relative to the fundamental grouping of CYGNSS wind measurements (a common track of specular points), and thus ensured spatial and temporal continuity.

It is not clear how a different matchup approach could provide comparable spatial and temporal proximity, because the specular reflections provided by CYGNSS are fundamentally sparser in time and space than a swath-based measurement. For example, it is not realistic for CYGNSS to provide contiguous coverage of the winds in a mesoscale convective system (MCS) within the lifetime of said MCS (i.e., a few hours). ASCAT can provide swath coverage of winds (and thus a contiguous snapshot 
of the wind field), but this approach was not considered because the focus of this study was primarily on CYGNSS due to its ability to retrieve winds in heavy rain.

Figure 2 shows an example of how a track that contained winds near precipitation with lightning appears. The portions of the track marked in magenta (Figure $2 b$ ) indicate what was considered in the "winds with lightning" and "precipitation with lightning") categories. A comparable track, but with no lightning anywhere along it, would have the raining portions included in the "winds without lightning" category. The matched ASCAT-A winds agree well with CYGNSS FDS winds in the west swath, but there is significant disagreement in the east, with the largest deviations occurring within the co-observed raining area (Figure $2 b$ ). The tendency for ASCAT winds to increase significantly relative to CYGNSS within raining areas was observed in many matched tracks. Additionally, at the east edge of the track, where RCG decreased below 10, CYGNSS wind speeds became noticeably noisier.
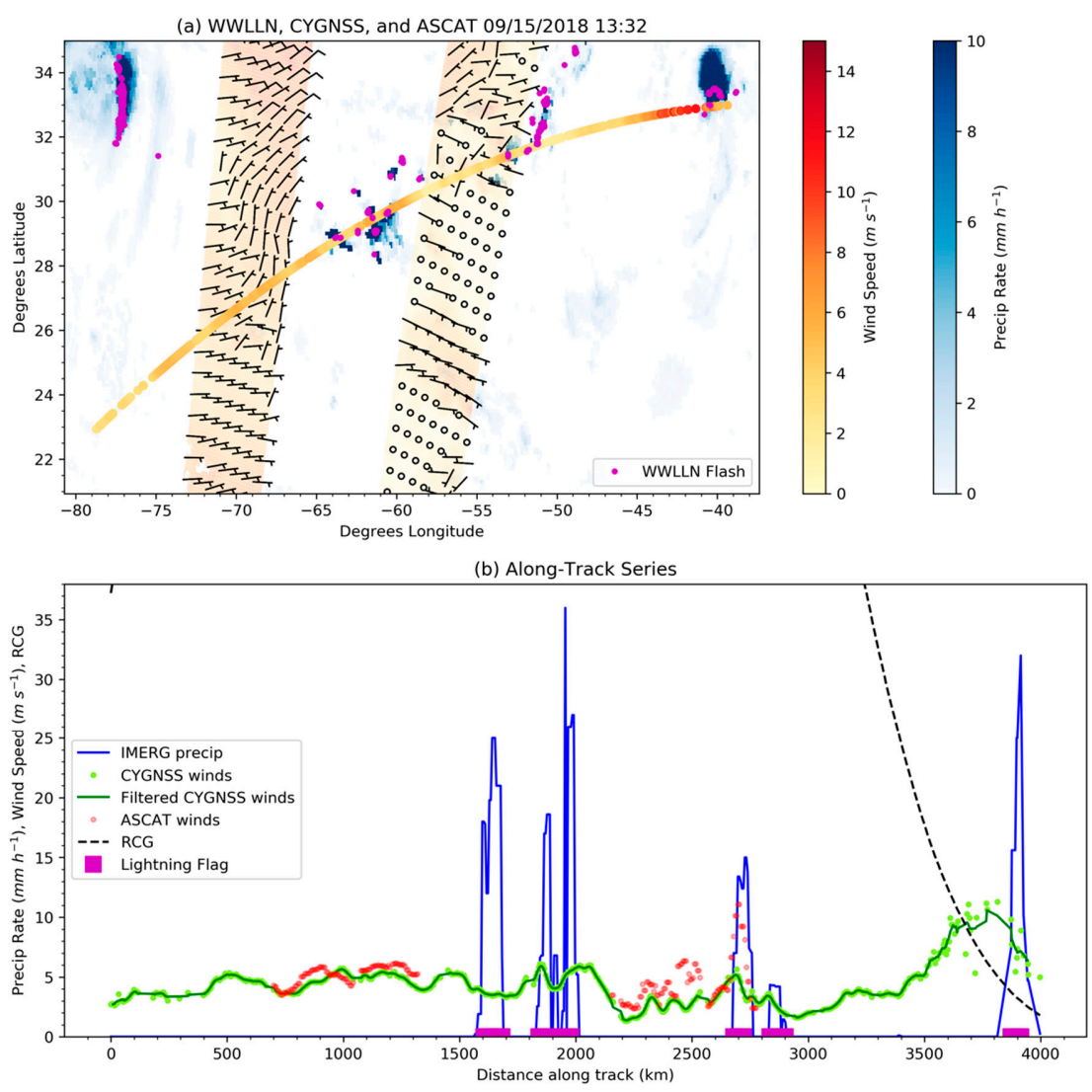

Figure 2. (a) Example of a CYGNSS track (arc of colored wind speeds) on a latitude/longitude map, along with ASCAT-A wind speeds (dual swaths) and wind barbs (black; circles $<5 \mathrm{~m} \mathrm{~s}^{-1}$ speed) for the matching orbit. IMERG precipitation rate is also shown, as are WWLLN flashes during the track (magenta dots). (b) Along-track series of CYGNSS FDS wind speeds (raw and filtered using a 5-point boxcar mean), matched ASCAT-A wind speeds, matched IMERG precipitation rate, and CYGNSS RCG. Shown also are flagged raining features with WWLLN lightning (magenta bars).

\section{Results}

\subsection{Global comparison of CYGNSS and ASCAT}

Before delving into the analysis of lightning, it is useful to understand how CYGNSS FDS winds and ASCAT winds compare in a general sense. This will provide valuable context for interpreting the lightning-wind results. For the following analysis, matched tracks for the time period 1 May 2017 through 31 December 2019 were used. Table 1 shows basic statistics for the 32-month period. The comparisons were very similar whether ASCAT-A or -B was used. CYGNSS 
FDS winds - the retrieval approach appropriate for non-tropical cyclone wind strengths-had a root mean square difference (RMSD) with ASCAT-A and -B of less than $2 \mathrm{~m} \mathrm{~s}^{-1}$ when matched IMERG rain rates were zero, which was within the expected uncertainty for CYGNSS [20,37]. CYGNSS wind speeds averaged approximately $0.5 \mathrm{~m} \mathrm{~s}^{-1}$ stronger than ASCAT in non-raining circumstances.

Table 1. RMSD, mean offset, and number of matchups for winds outside of rain and winds in rain. Convention is CYGNSS FDS wind speeds minus ASCAT wind speeds (positive offset: CYGNSS winds were stronger).

\begin{tabular}{ccc}
\hline Variable & ASCAT-A & ASCAT-B \\
\hline No Rain RMSD $\left(\mathrm{m} \mathrm{s}^{-1}\right)$ & 1.94 & 1.93 \\
No Rain Offset $\left(\mathrm{m} \mathrm{s}^{-1}\right)$ & +0.52 & +0.53 \\
No Rain Matchups & $39,763,736$ & $40,099,155$ \\
Rain RMSD $\left(\mathrm{m} \mathrm{s}^{-1}\right)$ & 2.47 & 2.46 \\
Rain Offset $\left(\mathrm{m} \mathrm{s}^{-1}\right)$ & +0.45 & +0.47 \\
Rain Matchups & $4,238,318$ & $4,275,117$ \\
\hline
\end{tabular}

However, when IMERG rain rates were nonzero, the RMSD increased by $\sim 0.5 \mathrm{~m} \mathrm{~s}^{-1}$, while the mean offset decreased slightly. There was approximately a factor of 10 reduction in the available number of matchups in rain, compared to non-raining matchups.

The magnitudes of the offset and RMSD changes in rain increased as rain rate increased (Figure 3). To develop Figure 3, the raining statistics were reevaluated at increasing thresholds for minimum rain rate. RMSD increased quasi-asymptotically toward $\sim 4 \mathrm{~m} \mathrm{~s}^{-1}$ as rain rate increased toward $30 \mathrm{~mm} \mathrm{~h}^{-1}$ (Figure 3a). Meanwhile, the slight positive offset for CYGNSS wind speeds rapidly became negative (ASCAT wind speeds stronger), reaching approximately $-2 \mathrm{~m} \mathrm{~s}^{-1}$ once rain rate reached $30 \mathrm{~mm} \mathrm{~h}^{-1}$ (Figure 3b). Approximately 95\% of raining matchups occurred in rain rates below $5 \mathrm{~mm} \mathrm{~h}^{-1}$, so results above this threshold were increasingly more uncertain as rain rate increased.
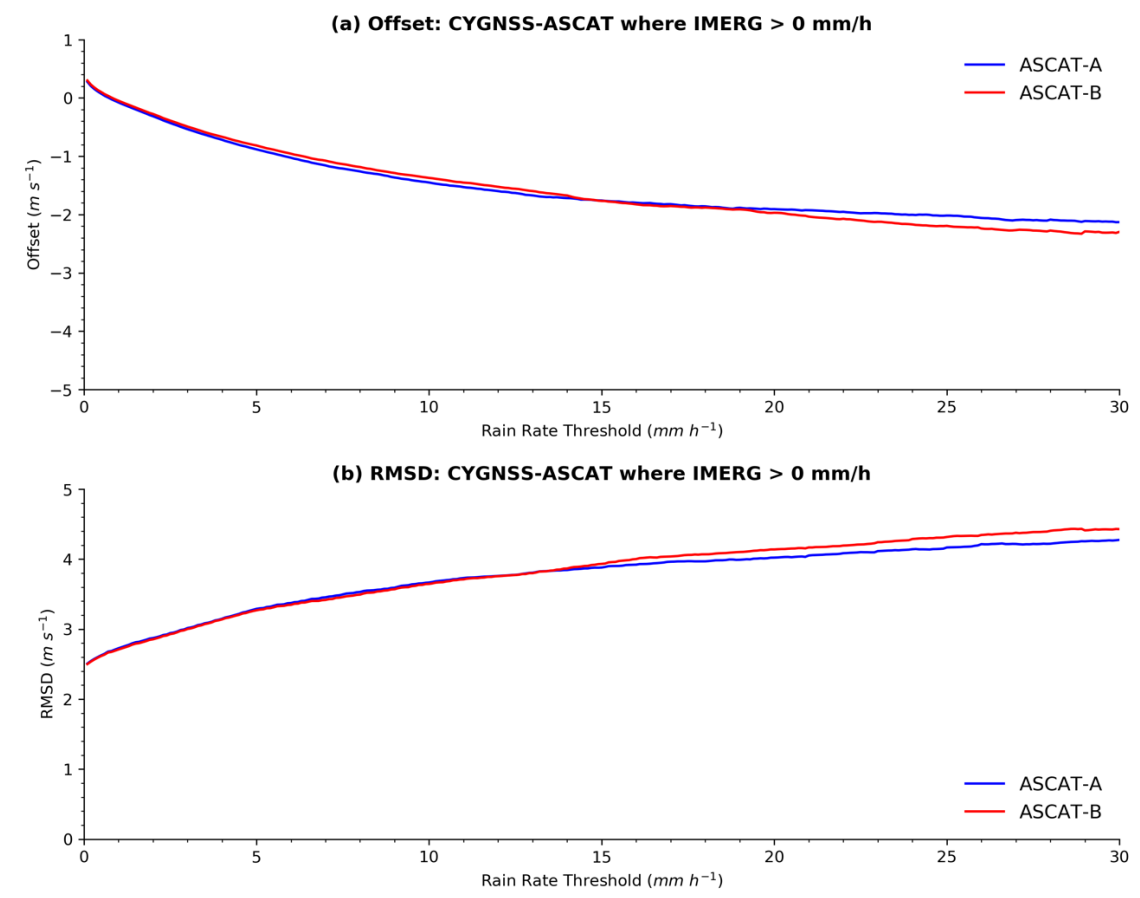

Figure 3. (a) Mean offsets between CYGNSS FDS and ASCAT-A and -B wind speeds as a function of IMERG rain rate, conditioned on the rain rate being nonzero. (b) RMSD between CYGNSS FDS and ASCAT-A and -B wind speeds as a function of IMERG rain rate, conditioned on the rain rate being nonzero. All data were from May 2017 through December 2019. 
Figure 4 shows that RMSD and mean offset have, in general, been increasing with time against both ASCAT-A (Figure 4a) and -B (Figure 4b). This was likely due to increasing uncertainty in GPS power calibration, which affects the CYGNSS v2.1 wind retrieval. Newer versions of CYGNSS data are expected to have improved performance, and should remove these trends. In summary, we expect reduced agreement between CYGNSS and ASCAT in rain, and the 2019 matchups should show worse agreement than 2018. In particular, this comparison demonstrates that the ASCAT wind speed enhancement in rainfall (and reduced agreement with CYGNSS), shown in the Figure 2b sample track, was a general trend observed in the overall CYGNSS track dataset.
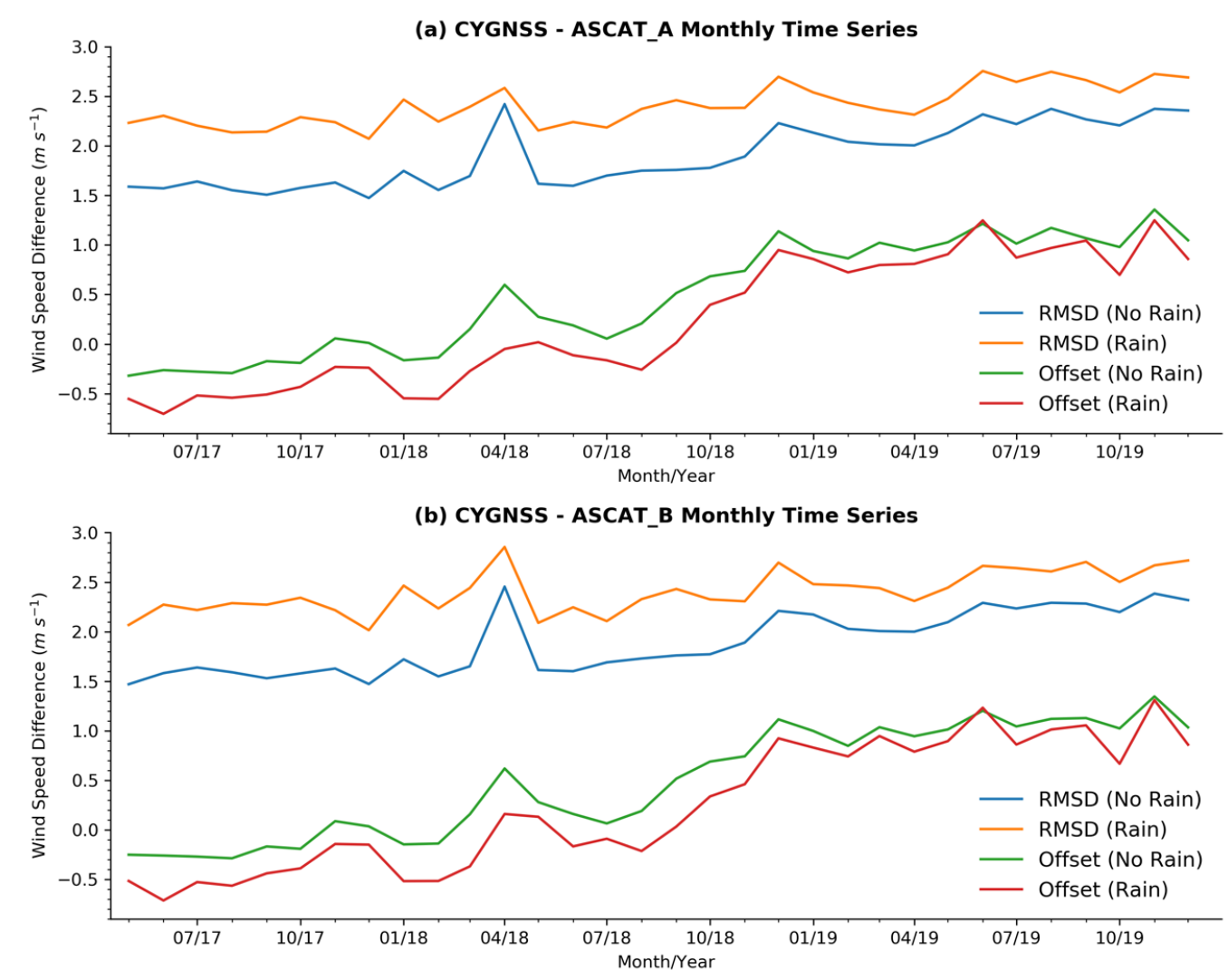

Figure 4. (a) Monthly time series of RMSD and mean offsets between CYGNSS FDS and ASCAT-A wind speeds, for zero and nonzero IMERG rain rates. (b) Monthly time series of RMSD and mean offsets between CYGNSS FDS and ASCAT-B wind speeds, for zero and nonzero IMERG rain rates. All data are for May 2017 through December 2019.

\subsection{Lightning Analysis}

\subsubsection{Overall Statistics}

The statistics for track matchups with WWLLN are shown in Table 2. Recall that the WWLLN period of analysis was August-October during 2018 and 2019. Surprisingly, the CYGNSS FDS winds not associated with lightning had slightly higher speeds (by $\sim 0.2 \mathrm{~m} \mathrm{~s}^{-1}$ ) compared to winds associated with lightning. This difference was small but greatly exceeded the $99 \%$ confidence intervals for the mean of either category. The difference was also robust if the restrictions were placed, either requiring RCG to exceed 10 or the rain rate to be less than $6 \mathrm{~mm} \mathrm{~h}^{-1}$ (to control for any possible rain effects). YSLF winds also showed a similar pattern, but with reduced differences between the two categories. 
Table 2. Summary statistics for winds and precipitation both associated and not associated with WWLLN lightning.

\begin{tabular}{|c|c|c|c|c|c|}
\hline Variable & Mean & 99\% Conf. Int. $( \pm)$ & Samples & $\begin{array}{l}\text { RCG }>10 \\
\text { (Mean) }\end{array}$ & $\begin{array}{c}\text { Rain }<6 \mathrm{~mm} \mathrm{~h}^{-1} \\
(\text { Mean) }\end{array}$ \\
\hline $\begin{array}{l}\text { CYGNSS FDS with } \\
\text { WWLLN }\left(\mathrm{m} \mathrm{s}^{-1}\right)\end{array}$ & 8.44 & 0.01 & $1,184,585$ & 8.61 & 8.34 \\
\hline $\begin{array}{l}\text { CYGNSS FDS without } \\
\text { WWLLN }\left(\mathrm{m} \mathrm{s}^{-1}\right)\end{array}$ & 8.62 & 0.00 & $15,227,308$ & 8.85 & 8.59 \\
\hline $\begin{array}{l}\text { CYGNSS YSLF with } \\
\text { WWLLN }\left(\mathrm{m} \mathrm{s}^{-1}\right)\end{array}$ & 9.14 & 0.01 & $1,176,396$ & 8.91 & 9.00 \\
\hline $\begin{array}{l}\text { CYGNSS YSLF without } \\
\text { WWLLN }\left(\mathrm{m} \mathrm{s}^{-1}\right)\end{array}$ & 9.25 & 0.00 & $15,075,239$ & 8.96 & 9.19 \\
\hline $\begin{array}{c}\text { ASCAT with } \\
\text { WWLLN }\left(\mathrm{m} \mathrm{s}^{-1}\right)\end{array}$ & 8.52 & 0.03 & 97,220 & N/A & 8.14 \\
\hline $\begin{array}{l}\text { ASCAT without } \\
\text { WWLLN }\left(\mathrm{m} \mathrm{s}^{-1}\right)\end{array}$ & 8.12 & 0.01 & $1,273,200$ & N/A & 8.05 \\
\hline $\begin{array}{c}\text { IMERG with } \\
\text { WWLLN }\left(\mathrm{mm} \mathrm{h}^{-1}\right)\end{array}$ & 2.95 & 0.01 & $1,184,585$ & N/A & N/A \\
\hline $\begin{array}{c}\text { IMERG without } \\
\text { WWLLN }\left(\mathrm{mm} \mathrm{h}^{-1}\right)\end{array}$ & 0.89 & 0.00 & $15,227,308$ & N/A & N/A \\
\hline $\begin{array}{l}\text { CYGNSS Std. Dev. with } \\
\text { WWLLN }\left(\mathrm{m} \mathrm{s}^{-1}\right)\end{array}$ & 1.13 & 0.01 & 28,853 & N/A & N/A \\
\hline $\begin{array}{c}\text { CYGNSS Std. Dev. } \\
\text { without WWLLN }\left(\mathrm{m} \mathrm{s}^{-1}\right)\end{array}$ & 1.44 & 0.00 & 294,024 & N/A & N/A \\
\hline
\end{tabular}

In a sensitivity study to gauge differences in wind variability in precipitation with and without lightning, the standard deviation of CYGNSS FDS wind speeds in each contiguous region of precipitation along a track (e.g., each region marked by a magenta bar in Figure $2 b$ ) was analyzed. The results were similar to the mean wind speeds, with winds in precipitation without lightning about $30 \%$ more variable than in precipitation with lightning.

Compared to CYGNSS, an opposite pattern was observed for ASCAT winds, which were stronger when WWLLN lightning was present (by $\sim 0.4 \mathrm{~m} \mathrm{~s}^{-1}$ ) than without. However, the magnitude of this difference decreased to only $\sim 0.1 \mathrm{~m} \mathrm{~s}^{-1}$ when controlling for higher rain rates. Note that when ASCAT-A and -B winds were both matched to a particular CYGNSS specular point, all of the analyses in this Section 3.2 defaulted to ASCAT-A. As seen in Section 3.1, A and B are well calibrated against each other so this choice had no significant impact on the results compared to using B (or averaging) instead.

The largest differences between WWLLN lightning and no WWLLN lightning were for IMERG rain rates, which were larger by a factor of 3 on average when WWLLN lightning was present. In summary, the overall trend for CYGNSS was that winds were slightly stronger and more variable when WWLLN lightning was not present, even as precipitation rate increased significantly when lightning occurred. The opposite wind trend was observed in ASCAT winds, but there were fewer samples available, and the ASCAT difference was affected when controlling for precipitation rate.

Since WWLLN is most sensitive to CG lightning, it was possible that some intracloud- (IC-) only thunderstorms were being mistakenly included in the "winds without lightning" categories. Because GLM-16 is sensitive to total (CG + IC) lightning, it should be able to control for that uncertainty. Table 3 shows the equivalent statistics as Table 2, but for GLM lightning. The period of GLM analysis was July-December 2018 and 2019. This lengthened period enabled comparable sample numbers to the WWLLN analysis. 
Table 3. Summary statistics for winds and precipitation both associated and not associated with GLM lightning.

\begin{tabular}{|c|c|c|c|c|c|}
\hline Variable & Mean & 99\% Conf. Int. $( \pm)$ & Samples & $\begin{array}{c}\text { RCG }>10 \\
\text { (Mean) }\end{array}$ & $\begin{array}{c}\text { Rain }<6 \mathrm{~mm} \mathrm{~h}^{-1} \\
(\text { Mean) }\end{array}$ \\
\hline $\begin{array}{l}\text { CYGNSS FDS with GLM } \\
\qquad\left(\mathrm{m} \mathrm{s}^{-1}\right)\end{array}$ & 8.35 & 0.01 & 937,027 & 8.50 & 8.25 \\
\hline $\begin{array}{l}\text { CYGNSS FDS without } \\
\text { GLM }\left(\mathrm{m} \mathrm{s}^{-1}\right)\end{array}$ & 8.72 & 0.00 & $19,673,569$ & 8.92 & 8.69 \\
\hline $\begin{array}{l}\text { CYGNSS YSLF with GLM } \\
\qquad\left(\mathrm{m} \mathrm{s}^{-1}\right)\end{array}$ & 8.84 & 0.02 & 929,953 & 8.58 & 8.69 \\
\hline $\begin{array}{l}\text { CYGNSS YSLF without } \\
\text { GLM }\left(\mathrm{m} \mathrm{s}^{-1}\right)\end{array}$ & 9.24 & 0.00 & $19,534,703$ & 8.97 & 9.20 \\
\hline $\begin{array}{l}\text { ASCAT with } \\
\operatorname{GLM}\left(\mathrm{m} \mathrm{s}^{-1}\right)\end{array}$ & 8.72 & 0.03 & 79,225 & N/A & 8.37 \\
\hline $\begin{array}{l}\text { ASCAT without GLM } \\
\qquad\left(\mathrm{m} \mathrm{s}^{-1}\right)\end{array}$ & 8.10 & 0.01 & $1,752,437$ & $\mathrm{~N} / \mathrm{A}$ & 8.03 \\
\hline $\begin{array}{l}\text { IMERG with GLM } \\
\qquad\left(\mathrm{mm} \mathrm{h}^{-1}\right)\end{array}$ & 2.80 & 0.01 & 937,027 & $\mathrm{~N} / \mathrm{A}$ & N/A \\
\hline $\begin{array}{l}\text { IMERG without GLM } \\
\qquad\left(\mathrm{mm} \mathrm{h}^{-1}\right)\end{array}$ & 0.92 & 0.00 & $19,673,569$ & $\mathrm{~N} / \mathrm{A}$ & $\mathrm{N} / \mathrm{A}$ \\
\hline $\begin{array}{l}\text { CYGNSS Std. Dev. with } \\
\text { GLM }\left(\mathrm{m} \mathrm{s}^{-1}\right)\end{array}$ & 1.08 & 0.01 & 25,070 & N/A & N/A \\
\hline $\begin{array}{l}\text { CYGNSS Std. Dev. } \\
\text { without GLM }\left(\mathrm{m} \mathrm{s}^{-1}\right)\end{array}$ & 1.58 & 0.00 & 303,731 & N/A & N/A \\
\hline
\end{tabular}

GLM appeared to confirm that some misidentification of thunderstorms was occurring within the "without lightning" categories. In general, differences between the "with" and "without" categories were magnified, but the same basic trends were observed: CYGNSS winds were stronger and more variable in precipitation without lightning (by $\sim 0.4-0.5 \mathrm{~m} \mathrm{~s}^{-1}$ ), while ASCAT winds were stronger in precipitation with lightning by $\sim 0.6 \mathrm{~m} \mathrm{~s}^{-1}$ ). However, the CYGNSS differences were robust when controlling for heavy precipitation $\left(>6 \mathrm{~mm} \mathrm{~h}^{-1}\right)$, while ASCAT differences between the categories were reduced (to $<0.4 \mathrm{~m} \mathrm{~s}^{-1}$ ). The one exception to this intensified pattern was IMERG precipitation rate. This was still significantly stronger in precipitation with lightning than without, but the overall difference was slightly reduced compared to WWLLN (by $\sim 0.15-0.20 \mathrm{~mm} \mathrm{~h}^{-1}$ ).

Finally, ISS LIS statistics are shown in Table 4. The ISS LIS analysis covered 32 months during 2017-2019, and also provided global coverage, but, despite this, the number of samples was greatly reduced compared to the WWLLN or GLM-16 analyses. Regardless, the overall trends were very similar-CYGNSS FDS winds were stronger when ISS LIS-detected lightning was not present than when it was, while the opposite was observed for ASCAT. CYGNSS YSLF winds also followed this trend, but the difference was smaller, and it decreased when controlling for RCG but not for precipitation. However, CYGNSS winds appeared to be more slightly more variable when lightning was present. Note, however, that the available number of samples for several of the "with lightning" categories was much smaller than for the other two lightning instruments, so caution is warranted in interpreting these statistics. 
Table 4. Summary statistics for winds and precipitation both associated and not associated with ISS LIS lightning.

\begin{tabular}{|c|c|c|c|c|c|}
\hline Variable & Mean & 99\% Conf. Int. $( \pm)$ & Samples & $\begin{array}{l}\text { RCG }>10 \\
\text { (Mean) }\end{array}$ & $\begin{array}{c}\text { Rain }<6 \mathrm{~mm} \mathrm{~h}^{-1} \\
(\text { Mean) }\end{array}$ \\
\hline $\begin{array}{l}\text { CYGNSS FDS } \\
\text { with LIS }\left(\mathrm{m} \mathrm{s}^{-1}\right)\end{array}$ & 8.36 & 0.02 & 154,517 & 8.57 & 8.22 \\
\hline $\begin{array}{l}\text { CYGNSS FDS without LIS } \\
\qquad\left(\mathrm{m} \mathrm{s}^{-1}\right)\end{array}$ & 8.70 & 0.01 & $2,587,259$ & 8.90 & 8.67 \\
\hline $\begin{array}{l}\text { CYGNSS YSLF with LIS } \\
\left(\mathrm{m} \mathrm{s}^{-1}\right)\end{array}$ & 9.01 & 0.04 & 152,631 & 8.80 & 8.82 \\
\hline $\begin{array}{l}\text { CYGNSS YSLF without } \\
\text { LIS }\left(\mathrm{m} \mathrm{s}^{-1}\right)\end{array}$ & 9.19 & 0.01 & $2,568,336$ & 8.86 & 9.15 \\
\hline $\begin{array}{l}\text { ASCAT with } \\
\text { LIS }\left(\mathrm{m} \mathrm{s}^{-1}\right)\end{array}$ & 8.90 & 0.09 & 11,664 & N/A & 8.65 \\
\hline $\begin{array}{l}\text { ASCAT without } \\
\text { LIS }\left(\mathrm{m} \mathrm{s}^{-1}\right)\end{array}$ & 8.30 & 0.02 & 235,198 & N/A & 8.25 \\
\hline IMERG with LIS $\left(\mathrm{mm} \mathrm{h}^{-1}\right)$ & 3.43 & 0.04 & 154,517 & N/A & N/A \\
\hline $\begin{array}{l}\text { IMERG without } \\
\text { LIS }\left(\mathrm{mm} \mathrm{h}^{-1}\right)\end{array}$ & 0.96 & 0.00 & $2,587,259$ & N/A & N/A \\
\hline $\begin{array}{l}\text { CYGNSS Std. Dev. with } \\
\text { LIS }\left(\mathrm{m} \mathrm{s}^{-1}\right)\end{array}$ & 1.02 & 0.03 & 4,394 & N/A & N/A \\
\hline $\begin{array}{l}\text { CYGNSS Std. Dev. } \\
\text { without LIS }\left(\mathrm{m} \mathrm{s}^{-1}\right)\end{array}$ & 0.87 & 0.01 & 147,278 & N/A & N/A \\
\hline
\end{tabular}

The overall statistical results, common to all lightning instruments, were the following. CYGNSS FDS winds were stronger when lightning was not present (by $\sim 0.2-0.4 \mathrm{~m} \mathrm{~s}^{-1}$ ), and this was largely robust against controls for RCG or precipitation rate. ASCAT winds tended to be stronger when lightning was present (by $\sim 0.4-0.6 \mathrm{~m} \mathrm{~s}^{-1}$ ), but this difference was reduced significantly when controlling for heavier precipitation. Meanwhile, the percentage change in precipitation when lightning was present was much larger than the change in winds $(\sim 200-270 \%$ increase in rain rate when lightning occurred).

\subsubsection{Trends versus Precipitation Rates}

The general results presented in Tables $2-4$ were interrogated more deeply by examining how differences in categories behaved as functions of rain rate and lightning flash rate. For this analysis, rather than examining absolute wind speeds, the mean wind speed along each track was first subtracted from the wind speeds in each raining feature along the same track. This was done to determine the extent to which the results in Tables 2-4 were affected by the influence of larger-scale environmental winds.

Figure 5 shows the results for CYGNSS FDS and ASCAT mean wind differences as functions of IMERG precipitation rate. Whether the precipitation is associated with lightning or not, CYGNSS winds start roughly $1 \mathrm{~m} \mathrm{~s}^{-1}$ above background, indicating that precipitation is associated with stronger winds. For very light rain rates $\left(<1 \mathrm{~mm} \mathrm{~h}^{-1}\right)$ CYGNSS does see slightly higher wind speed differences when WWLLN lightning is present (Figure $5 \mathrm{a}$ ), but this trend quickly reverses as rain rate increases and winds without WWLLN lightning obtain and maintain a $\sim 0.5 \mathrm{~m} \mathrm{~s}^{-1}$ advantage for rain rates above $\sim 5 \mathrm{~mm} \mathrm{~h}^{-1}$. Wind speed differences increase slowly with precipitation rate after $\sim 5 \mathrm{~mm} \mathrm{~h}^{-1}$ as well. For ASCAT winds (Figure 5b), the differences from CYGNSS are significant. Like CYGNSS, ASCAT wind speeds in precipitation start about $1 \mathrm{~m} \mathrm{~s}^{-1}$ above background, and winds with WWLLN lightning are slightly stronger. However, unlike CYGNSS that $\sim 0.5 \mathrm{~m} \mathrm{~s}^{-1}$ advantage for winds with lightning is maintained as rain rate increases until at least $15 \mathrm{~mm} \mathrm{~h}^{-1}$, when the $99 \%$ confidence intervals between the curves 
start to overlap. Wind speed differences above background also increase more sharply as precipitation rate increases (both with and without WWLLN lightning), compared to CYGNSS.
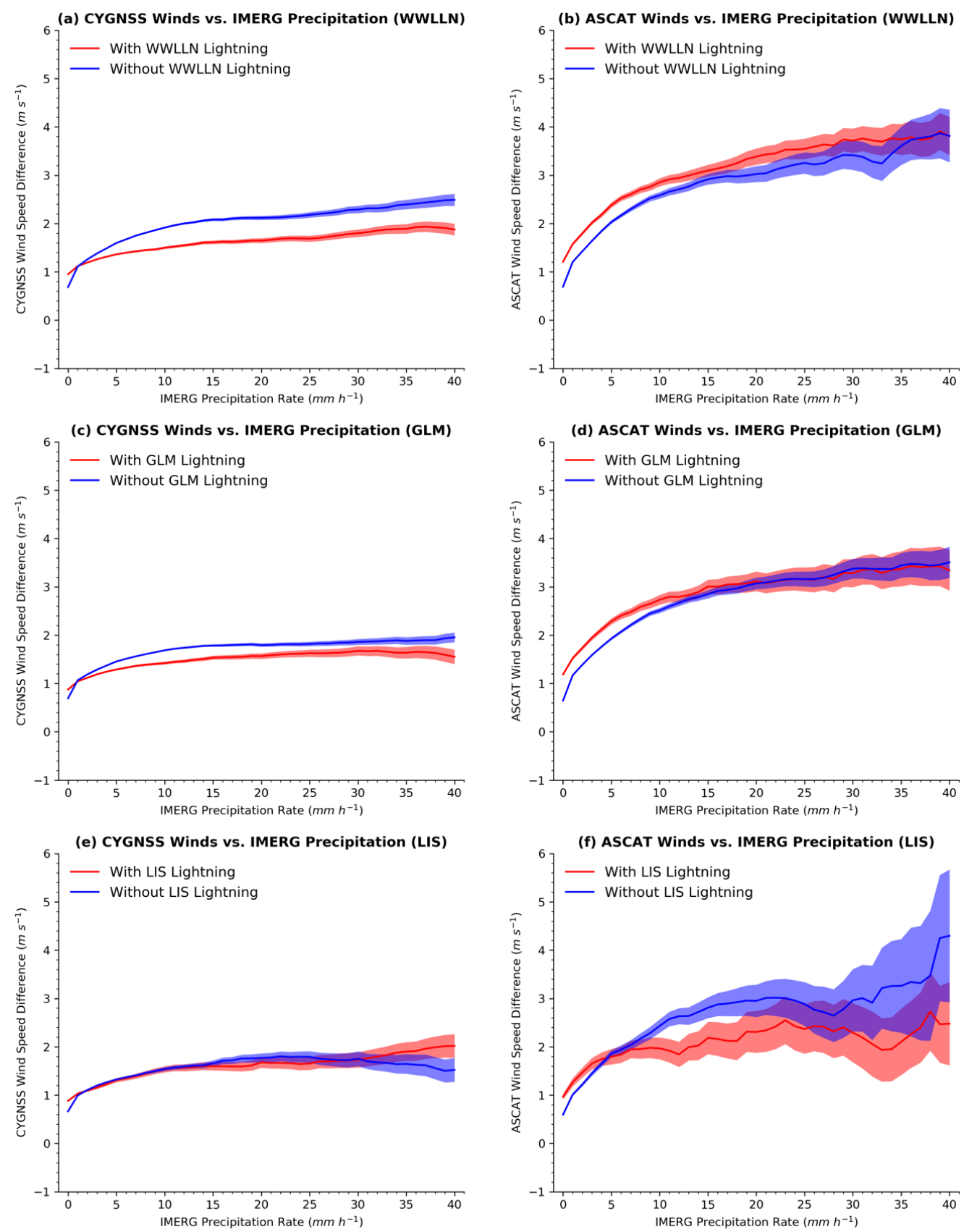

Figure 5. (a) CYGNSS FDS wind differences as functions of IMERG precipitation rate, for wind observations associated with WWLLN lightning and those not. (b) ASCAT wind differences as functions of IMERG precipitation rate, for wind observations associated with WWLLN lightning and those not. (c) CYGNSS FDS wind differences as functions of IMERG precipitation rate, for wind observations associated with GLM lightning and those not. (d) ASCAT wind differences as functions of IMERG precipitation rate, for wind observations associated with GLM lightning and those not. (e) CYGNSS FDS wind differences as functions of IMERG precipitation rate, for wind observations associated with ISS LIS lightning and those not. (f) ASCAT wind differences as functions of IMERG precipitation rate, for wind observations associated with ISS LIS lightning and those not. In all figures, the shaded areas indicate the $99 \%$ confidence interval in each $1 \mathrm{~mm} \mathrm{~h}^{-1} \mathrm{bin}$. 
The GLM analysis shows a similar pattern. For CYGNSS (Figure 5c), the gap between winds without and without GLM lightning narrows relative to WWLLN, though this is not true for ASCAT (Figure 5d). This narrowing for CYGNSS could reflect more accurate separation between the "with lightning" and "without lightning" categories, since GLM detects total lightning rather than primarily CGs like WWLLN. For ISS LIS and CYGNSS (Figure 5e), the gap between the two wind categories narrows to the point of overlap above $\sim 1 \mathrm{~mm} \mathrm{~h}^{-1}$. For ASCAT and ISS LIS (Figure $5 \mathrm{f}$ ), a similar pattern to GLM and WWLLN is seen, but the two curves are closer and start to overlap at $5 \mathrm{~mm} \mathrm{~h}^{-1}$. It is possible that the reduced samples for ISS LIS may be contributing to the greater volatility in the curves at higher rain rates.

Overall, Figure 5 confirms and expands upon the basic statistics shown in Tables 2-4. For CYGNSS, differences between winds associated with lightning and those not are reduced for total lightning sensors like GLM and ISS LIS. Moreover, the difference between the two wind categories (maximized around $+0.5 \mathrm{~m} \mathrm{~s}^{-1}$ for WWLLN, but much smaller for GLM and especially ISS LIS), is significantly smaller than the overall increase in wind speeds above background when precipitation is present $\left(+1-2 \mathrm{~m} \mathrm{~s}^{-1}\right.$, depending on precipitation rate). Winds associated with lightning are slightly stronger when precipitation rate is low $\left(<1 \mathrm{~m} \mathrm{~s}^{-1}\right)$, but that changes as precipitation rate increases and winds associated with WWLLN and GLM lightning are slightly weaker than winds not associated with lightning. Similar to Figure 3, ASCAT winds increase more rapidly than CYGNSS as rain rate increases (Figure $5 \mathrm{~b}, \mathrm{~d}, \mathrm{f}$ ). However, for all lightning sensors below at least $5 \mathrm{~mm} \mathrm{~h}^{-1}$ rain rate, ASCAT winds are stronger when lightning is present (by up to $0.5 \mathrm{~m} \mathrm{~s}^{-1}$ ). Recall, however, the fewer samples available for ASCAT in the analysis.

\subsubsection{Trends versus Flash Rates}

Figure 6 shows behavior of CYGNSS and ASCAT wind differences above background as functions of lightning flash rate. For CYGNSS, both FDS and YSLF wind speed differences decrease when WWLLN flash rates increase slightly above $0 \mathrm{~min}^{-1}$ (Figure 6a). This confirms the results in Table 2, where wind speeds associated with lightning were less than when lightning was present. However, as flash rate increases above $1 \mathrm{~min}^{-1}$, a quasi-linear increase in wind speed difference is observed, particularly for YSLF winds. However, uncertainty also increases since the number of high-flash-rate samples is low relative to $0-2 \mathrm{~min}^{-1}$ flash rates. ASCAT observes a sharper increase in wind speed difference as flash rate increases (Figure 6b); however, when controlling for higher rain rates $\left(>6 \mathrm{~mm} \mathrm{~h}^{-1}\right)$ the trend is almost flat until about $20 \mathrm{~min}^{-1}$, when the lack of samples begins to lead to dubious results.

Interestingly, CYGNSS wind differences show very little variability relative to GLM flash rates above $\sim 1 \mathrm{~min}^{-1}$ (Figure 6a). The initial decrease between 0 and $1 \mathrm{~min}^{-1}$ is observed, similar to WWLLN (Figure 6a), but above that range the relationship is essentially flat for both FDS and YSLF winds. Analogous behavior to WWLLN is observed for ASCAT wind differences versus GLM flash rates (Figure 6d). Once again a positive relationship is observed when not controlling for precipitation, but when controlling for heavier precipitation the ASCAT relationship is much flatter, similar to CYGNSS. Note that GLM provided more samples at higher flash rates $\left(>20 \mathrm{~min}^{-1}\right)$ since it is a total flash rate instrument, unlike WWLLN.

ISS LIS shows a weak positive relationship between FDS and YSLF wind differences and flash rate up to about $30 \mathrm{~min}^{-1}$, and the initial decrease in wind difference between 0 and $1 \mathrm{~min}^{-1}$ is not as strong compared to WWLLN and GLM (Figure 6e). However, uncertainty in this possible relationship is large enough that it cannot be distinguished from the complete lack of a relationship, based on the spreads of the $99 \%$ confidence intervals. ASCAT winds also show a positive relationship with flash rate, even when controlling for precipitation (Figure 6f). However, since ISS LIS provided fewer overall samples it is possible that these relationships are not robust. The $99 \%$ confidence interval spread for the ASCAT data is very large. 
(a) CYGNSS Winds vs. WWLLN Flash Rate

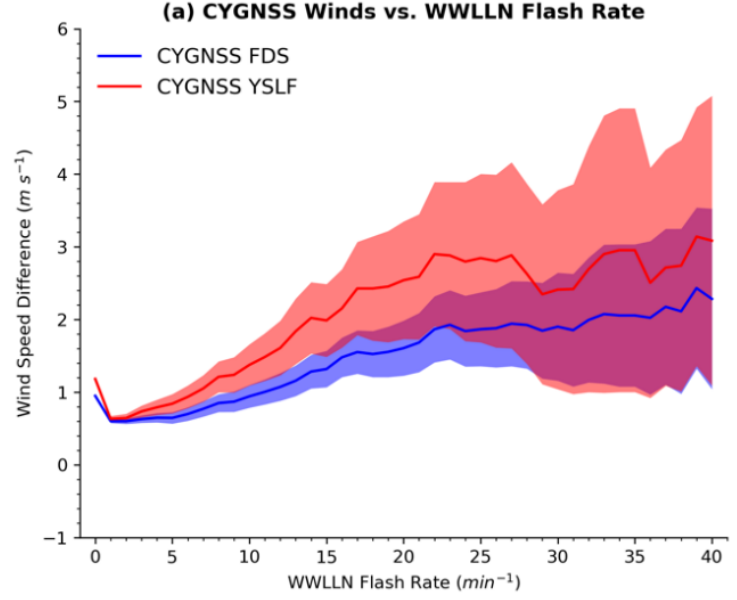

(c) CYGNSS Winds vs. GLM Flash Rate

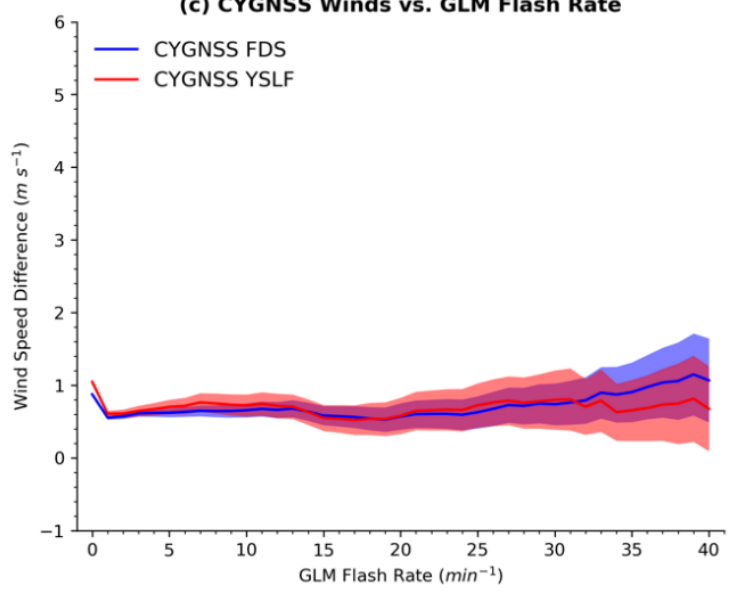

(e) CYGNSS Winds vs. LIS Flash Rate

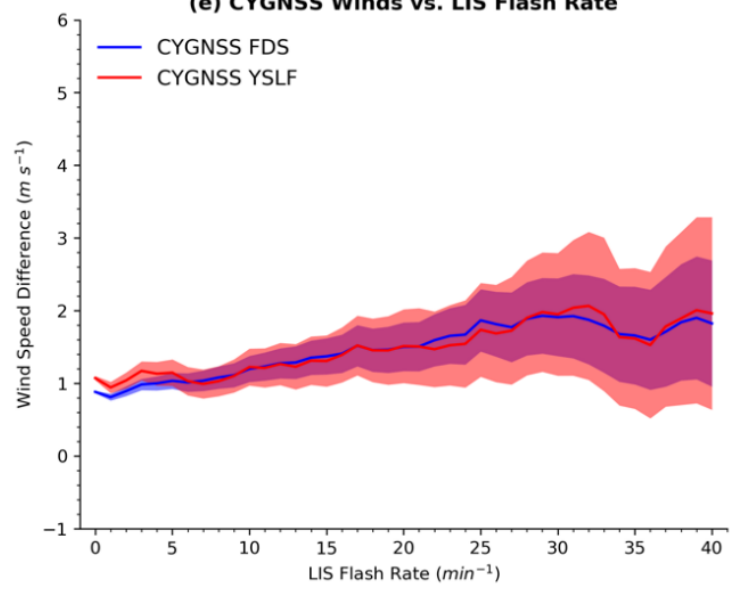

(b) ASCAT Winds vs. WWLLN Flash Rate

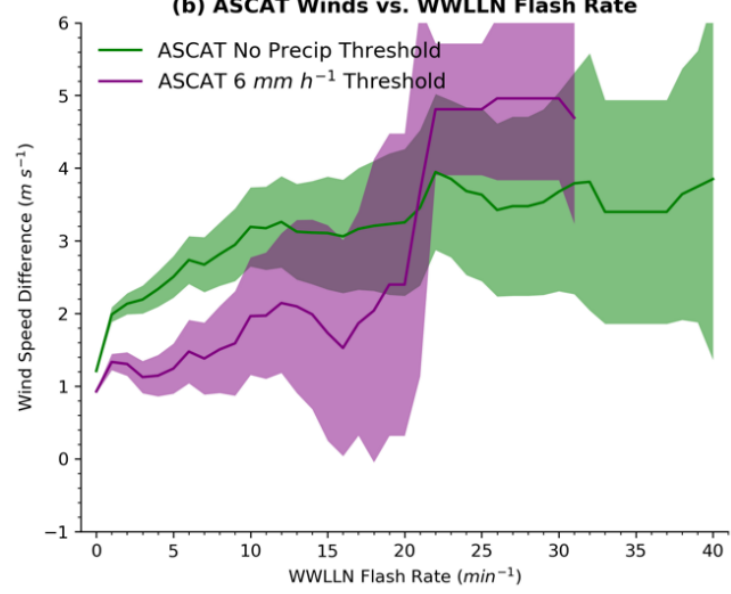

(d) ASCAT Winds vs. GLM Flash Rate

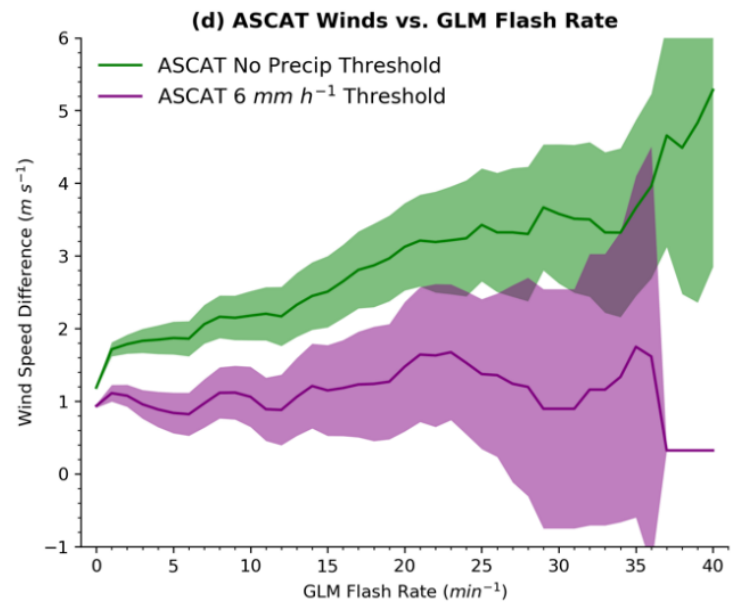

(f) ASCAT Winds vs. LIS Flash Rate

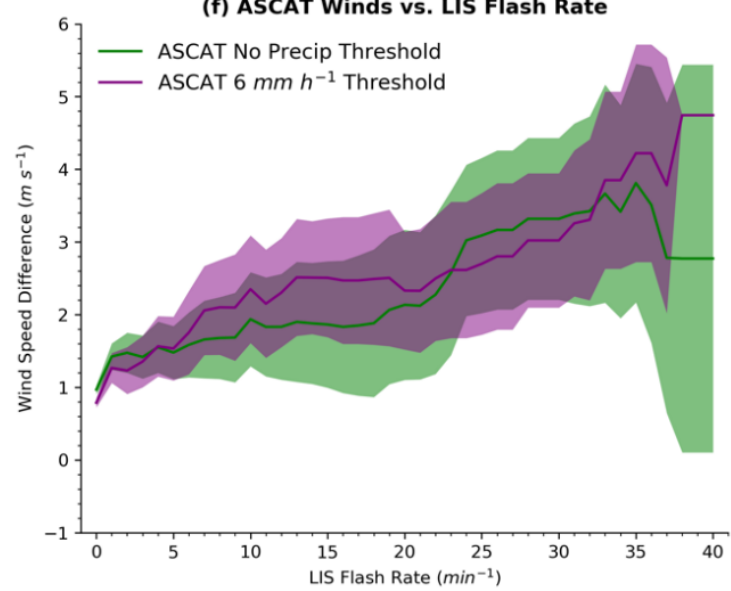

Figure 6. (a) CYGNSS FDS and YSLF wind differences as functions of WWLLN flash rate. (b) ASCAT wind differences as functions of WWLLN flash rate, for ASCAT observations associated with all precipitation rates and for ASCAT observations with precipitation rate $<6 \mathrm{~mm} \mathrm{~h}^{-1}$. (c) CYGNSS FDS and YSLF wind differences as functions of GLM flash rate. (d) ASCAT wind differences as functions of GLM flash rate, for ASCAT observations associated with all precipitation rates and for ASCAT observations with precipitation rate $<6 \mathrm{~mm} \mathrm{~h}^{-1}$. (e) CYGNSS FDS and YSLF wind differences as functions of GLM flash rate. (f) ASCAT wind differences as functions of GLM flash rate, for ASCAT observations associated with all precipitation rates and for ASCAT observations with precipitation rate $<6 \mathrm{~mm} \mathrm{~h}^{-1}$. In all figures, the shaded areas indicate the $99 \%$ confidence interval in each $1 \mathrm{~min}^{-1} \mathrm{bin}$. 


\section{Discussion}

Focusing first on the existing broad agreement between CYGNSS and matched ASCAT-A and -B wind data near precipitation systems, both types of sensors-despite their very different approaches to wind retrievals-agree that when light precipitation is present wind speeds are approximately $1 \mathrm{~m} \mathrm{~s}^{-1}$ greater than background (Figure 5). This is largely consistent with the independent studies of $[3,4]$. Additionally, regardless of the analysis approaches used in this study, the mean wind speeds from CYGNSS and matched ASCAT agree to within approximately $0.5 \mathrm{~m} \mathrm{~s}^{-1}$ (Tables 1-4). Finally, and most importantly for this paper, both CYGNSS and ASCAT agree that-if there is a difference in wind speeds near lightning-producing and non-lightning-producing precipitation systems, in the aggregate this effect is small $\left(\sim 0.2-0.6 \mathrm{~m} \mathrm{~s}^{-1}\right)$, and the overall percentage change in wind speed is much smaller than the observed percentage change in precipitation rate when lightning is occurring (i.e., $\sim 50 \%$ change in mean wind speed vs. $>200 \%$ change in precipitation rate; Tables $2-4$ ). These findings demonstrate the utility of combining distinct satellite-based precipitation and wind datasets to infer wind characteristics near precipitation systems.

Despite the above agreement, there are important differences observed that speak to remaining uncertainties in wind retrievals in and near rainfall. For example, regardless of whether lightning is occurring, ASCAT shows a stronger positive relationship between wind speed and IMERG precipitation rate compared to CYGNSS (Figure 5). Moreover, CYGNSS and ASCAT tend to fundamentally disagree on the sign of the change in wind speed between precipitation systems with and without lightning-ASCAT tends to observe slightly stronger winds when lightning is present, while CYGNSS tends to observe the opposite.

There is substantial evidence (e.g., Tables 1-4, Figures 3-6) that this disagreement stems from fundamental differences in winds measurements between the two sensors in rain. Because CYGNSS is an L-band sensor, it is thought to be potentially less sensitive to rain impacts compared to the C-band ASCAT [20]. The relatively larger sensitivity of the ASCAT results to precipitation rate compared to the CYGNSS results (e.g., Tables 2-4, Figures 5 and 6) supports this inference. Indeed, as [16-18] have shown, ASCAT wind retrievals in rain rates above $\sim 6 \mathrm{~mm} \mathrm{~h}^{-1}$ are likely less accurate. Thus, it makes sense that controlling for precipitation in this study's dataset showed much greater response in the ASCAT dataset. Note also that disagreements between CYGNSS and ASCAT results were reduced when controlling for rain.

However, CYGNSS likely does experience some impact on its wind speed measurements in rainfall, particularly when wind speed is low [38-41]. Moreover, uncertainties in the representativeness of both sensors' geophysical model functions (GMFs) near convection need to be considered. Apart from effects of signal attenuation and capillary waves from rain splash, winds near convection tend to be highly variable and change much faster than the ocean surface waves influenced by background winds can react [42]. Such phenomena will affect the wind retrievals from both types of sensors, and likely causes some of the observed differences since the CYGNSS and ASCAT observations are not matched perfectly in time (approximately a \pm 45 -min window, based on the matching criteria described in Section 2.2).

Tropical cyclones were included in the analysis but were not broken out in the statistics. As argued in Section 2.1, they likely did not significantly impact the results due to their rarity relative to conventional tropical precipitation systems. However, it is possible that tropical cyclones were responsible for a small part of the observed ASCAT/CYGNSS discrepancies. For example, CYGNSS FDS winds are not generally valid in tropical cyclones as their retrieval algorithm generally does not provide wind speeds in excess of $20 \mathrm{~m} \mathrm{~s}^{-1}$, while the YSLF retrieval algorithm allows for higher wind speeds [20]. Thus, comparing CYGNSS FDS to ASCAT in tropical cyclones would result in a low bias in CYGNSS winds. However, CYGNSS YSLF results were similar to the FDS results, supporting the inference that tropical cyclones were not significantly impacting the overall statistics.

An additional possible influence on the results is the effect of the CYGNSS v2.1 dataset, which was afflicted by variability in calibration, both in time (e.g., Figure 4) as well as between different specular 
point tracks. This is a known issue that is substantively addressed by track-wise debiasing in the new climate data record (CDR) v1.0 dataset [43]. Select months from this dataset were processed the same way as v2.1 (c.f. Section 2), but the results were not significantly different than for v2.1 (not shown). This is likely because CDR v1.0 does not appear to significantly improve CYGNSS and ASCAT agreement in rainfall [44].

\section{Conclusions}

In order to examine how robust updraft strength and ice-based microphysical processes aloft in storms may affect convective outflows near the surface, ocean winds were compared between tropical maritime precipitation systems with and without lightning. The analysis focused on CYGNSS specular point tracks, using straightforward spatiotemporal matching criteria to pair CYGNSS-measured wind speeds with IMERG precipitation, ASCAT-A and -B wind speeds, and lightning flash data from WWLLN, GLM-16, and ISS LIS.

Based on the results, thunderstorms over the tropical oceans are clearly associated with significantly heavier rain rates ( $200 \%$ greater) than non-lightning-producing showers. This is consistent with past work on relationships between lightning and rainfall $[45,46]$. However, wind speeds near either type of precipitation system do not differ much $\left(\sim 0.5 \mathrm{~m} \mathrm{~s}^{-1}\right.$ or less). Moreover, the sign of the difference depends on the wind instrument used, with CYGNSS suggesting non-thunderstorm winds are (counterintuitively) slightly stronger, while ASCAT suggests the opposite. These observed wind differences are likely related to remaining uncertainties in the comparison of CYGNSS/ASCAT in precipitation (e.g., GMF uncertainties when winds are variable, rain impacts on measurement accuracy, etc.).

If ASCAT observations are considered more accurate in rainfall than CYGNSS, then the hypothesis that thunderstorms are associated with stronger surface outflows (suggesting also stronger cold pools) is supported by the available evidence. However, if this is not the case and CYGNSS winds are more accurate than ASCAT in rainfall, then there is not enough evidence to support the thunderstorm outflow hypothesis (indeed, the opposite argument might be made), which would be unexpected. However, it is possible that the dataset was well-populated with relatively weak, low-flash-rate thunderstorms (this is supported by the greater uncertainty in the Figure 6 curves when flash rates exceeded 1-2 $\mathrm{min}^{-1}$ ), which indeed may not feature significantly stronger surface winds than non-thunderstorms. In that case, the CYGNSS observations may be consistent with expectations. Another complicating factor to consider is that thunderstorms over the global ocean tend to be larger and more organized than those over land [47,48]. Thus, CYGNSS overpasses may sample stratiform precipitation in lightning-producing systems more often, where winds would be expected to be weaker than near, e.g., the leading-edge gust front. Regardless, both CYGNSS and ASCAT find winds near precipitation (whether lightning-producing or not) to be stronger than background by at least $1 \mathrm{~m} \mathrm{~s}^{-1}$, consistent with prior studies $[3,4]$.

Future work will focus on a longer period of record, improved CYGNSS wind datasets, and incorporating ASCAT into the analysis in a manner that preserves its swath-based observations. In addition, IMERG data are expected to improve with time. These changes may enable more accurate characterization of wind variability near precipitation systems. Moreover, future improvements to the GLM and ISS LIS datasets are expected to increase their effective detection efficiencies and reduce their false alarm rates $[32,33]$. This will mitigate remaining uncertainty in whether a precipitation system is a thunderstorm or not.

Funding: This research was funded by the CYGNSS, Ocean Vector Winds Science Team (OVWST), and Earth from ISS programs within the Science Mission Directorate (SMD) of the National Aeronautics and Space Administration (NASA).

Acknowledgments: This research benefitted from fruitful conversations about the various datasets used with the following people: D.M., K.V., S.N., P.G., G.P., C.R., Z.J., S.A., B.R., J.M., X. L., and R.B. The Physical Oceanography Distributed Active Archive Center (PO.DAAC) supplied the CYGNSS and ASCAT data. IMERG data were obtained from Goddard Space Flight Center. University of Washington supplied the WWLLN data. The Global Hydrology Resource Center (GHRC) DAAC supplied ISS LIS and GLM-16 data. 
Conflicts of Interest: The author declares no conflict of interest.

\section{References}

1. Thorpe, A.J.; Miller, M.J.; Moncrieff, M.W. Two-dimensional convection in non-constant shear: A model of mid-latitude squall lines. Q. J. R. Meteorol. Soc. 1982, 108, 739-762. [CrossRef]

2. Garg, P.; Nesbitt, S.W.; Lang, T.J.; Priftis, G.; Chronis, T.; Thayer, J.D.; Hence, D.A. Identifying and Characterizing Tropical Oceanic Mesoscale Cold Pools using Spaceborne Scatterometer Winds. J. Geophys. Res. Atmos. 2020, 125, e2019JD031812. [CrossRef]

3. De Szoeke, S.P.; Skyllingstad, E.D.; Zuidema, P.; Chandra, A. Cold Pools and Their Influence on the Tropical Marine Boundary Layer. J. Atmos. Sci. 2017, 74, 1149-1168. [CrossRef]

4. $\quad$ Feng, Z.; Hagos, S.; Rowe, A.K.; Burleyson, C.; Martini, M.N.; Szoeke, S.P. Mechanisms of convective cloud organization by cold pools over tropical warm ocean during the AMIE/DYNAMO field campaign. J. Adv. Model. Earth Syst. 2015, 7, 357-381. [CrossRef]

5. Atkins, N.T.; Wakimoto, R.M. Wet Microburst Activity over the Southeastern United States: Implications for Forecasting. Weather Forecast. 1991, 6, 470-482. [CrossRef]

6. Saunders, C.P.R.; Keith, W.D.; Mitzeva, R.P. The effect of liquid water on thunderstorm charging. J. Geophys. Res. Space Phys. 1991, 96, 11007-11017. [CrossRef]

7. Deierling, W.; Petersen, W.A. Total lightning activity as an indicator of updraft characteristics. J. Geophys. Res. Space Phys. 2008, 113. [CrossRef]

8. Deierling, W.; Petersen, W.A.; Latham, J.; Ellis, S.; Christian, H.J. The relationship between lightning activity and ice fluxes in thunderstorms. J. Geophys. Res. Space Phys. 2008, 113. [CrossRef]

9. Basarab, B.M.; Rutledge, S.A.; Fuchs, B.R. An improved lightning flash rate parameterization developed from Colorado DC3 thunderstorm data for use in cloud-resolving chemical transport models. J. Geophys. Res. Atmos. 2015, 120, 9481-9499. [CrossRef]

10. Carey, L.D.; Schultz, E.V.; Schultz, C.J.; Deierling, W.; Petersen, W.A.; Bain, A.L.; Pickering, K.E. An Evaluation of Relationships between Radar-Inferred Kinematic and Microphysical Parameters and Lightning Flash Rates in Alabama Storms. Atmosphere 2019, 10, 796. [CrossRef]

11. Petersen, W.A.; Christian, H.J.; Rutledge, S.A. TRMM observations of the global relationship between ice water content and lightning. Geophys. Res. Lett. 2005, 32, 14819. [CrossRef]

12. Price, C.; Rind, D. A simple lightning parameterization for calculating global lightning distributions. J. Geophys. Res. Space Phys. 1992, 97, 9919-9933. [CrossRef]

13. Lang, T.; Rutledge, S.A. A Framework for the Statistical Analysis of Large Radar and Lightning Datasets: Results from STEPS 2000. Mon. Weather Rev. 2011, 139, 2536-2551. [CrossRef]

14. Williams, E.; Boldi, B.; Matlin, A.; Weber, M.; Hodanish, S.; Sharp, D.; Goodman, S.; Raghavan, R.; Buechler, D. The behavior of total lightning activity in severe Florida thunderstorms. Atmos. Res. 1999, 51, 245-265. [CrossRef]

15. Schultz, C.J.; Carey, L.D.; Schultz, E.V.; Blakeslee, R.J. Insight into the Kinematic and Microphysical Processes that Control Lightning Jumps. Weather Forecast. 2015, 30, 1591-1621. [CrossRef]

16. Lin, W.; Portabella, M.; Stoffelen, A.; Verhoef, A.; Turiel, A. ASCAT Wind Quality Control Near Rain. IEEE Trans. Geosci. Remote Sens. 2015, 53, 4165-4177. [CrossRef]

17. Portabella, M.; Stoffelen, A.; Lin, W.; Turiel, A.; Verhoef, A.; Verspeek, J.; Ballabrera-Poy, J. Rain Effects on ASCAT-Retrieved Winds: Toward an Improved Quality Control. IEEE Trans. Geosci. Remote Sens. 2012, 50, 2495-2506. [CrossRef]

18. Kilpatrick, T.; Xie, S.-P. ASCAT observations of downdrafts from mesoscale convective systems. Geophys. Res. Lett. 2015, 42, 1951-1958. [CrossRef]

19. Ruf, C.; Chew, C.; Lang, T.J.; Morris, M.G.; Nave, K.; Ridley, A.; Balasubramaniam, R. A New Paradigm in Earth Environmental Monitoring with the CYGNSS Small Satellite Constellation. Sci. Rep. 2018, 8, 1-13. [CrossRef]

20. Ruf, C.S.; Asharaf, S.; Balasubramaniam, R.; Gleason, S.; Lang, T.; McKague, D.; Twigg, D.; Waliser, D. In-Orbit Performance of the Constellation of CYGNSS Hurricane Satellites. Bull. Am. Meteorol. Soc. 2019, 100, 2009-2023. [CrossRef] 
21. CYGNSS. CYGNSS Level 2 Science Data Record Version 2.1. Ver. 2.1; PO.DAAC: Pasadena, CA, USA, 2018; Available online: https://doi.org/10.5067/CYGNS-L2X21 (accessed on 1 January 2020).

22. Hoover, K.E.; Mecikalski, J.R.; Lang, T.J.; Li, X.; Castillo, T.J.; Chronis, T. Use of an End-to-End-Simulator to Analyze CYGNSS. J. Atmos. Ocean. Technol. 2018, 35, 35-55. [CrossRef] [PubMed]

23. Ester, M.; Kriegel, H.P.; Sander, J.; Xu, X. A Density-Based Algorithm for Discovering Clusters in Large Spatial Databases with Noise. In KDD-96: Proceedings: Proceedings of the 2nd International Conference on Knowledge Discovery and Data Mining, Portland, OR, USA, 2-4 August 1996; Simoudis, E., Han, J., Fayyad, U.M., Eds.; AAAI Press: Menlo Park, CA, USA, 1996; pp. 226-231.

24. PyGNSS. Python Interface to Cyclone Global Navigation Satellite System (CYGNSS) Wind Dataset. Available online: https://github.com/nasa/PyGNSS (accessed on 1 January 2020).

25. EUMETSAT/OSI SAF. MetOp-A ASCAT Level 2 Ocean Surface Wind Vectors Optimized for Coastal Ocean: Ver. Operational/Near-Real-Time; PO.DAAC: Pasadena, CA, USA, 2010. Available online: https://podaac.jpl. nasa.gov/dataset/ASCATA-L2-Coastal (accessed on 1 January 2020).

26. EUMETSAT/OSI SAF. MetOp-B ASCAT Level 2 Ocean Surface Wind Vectors Optimized for Coastal Ocean: Ver. Operational/Near-Real-Time; PO.DAAC: Pasadena, CA, USA, 2013. Available online: https://podaac.jpl. nasa.gov/dataset/ASCATA-L2-Coastal (accessed on 1 January 2020).

27. Huffman, G.J.; Bolvin, D.T.; Nelkin, E.J. Integrated Multi-SatellitE Retrievals for GPM (IMERG) Technical Documentation; NASA/GSFC Code612 Tech. Doc.; IMERG Tech Document: Greenbelt, MD, USA, 2015. Available online: http://pmm.nasa.gov/sites/default/files/document_files/IMERG_doc.pdf (accessed on 26 March 2020).

28. Hutchins, M.L.; Holzworth, R.H.; Brundell, J.B.; Rodger, C.J. Relative detection efficiency of the World Wide Lightning Location Network. Radio Sci. 2012, 47, 6005. [CrossRef]

29. Bürgesser, R.E. Assessment of the World Wide Lightning Location Network (WWLLN) detection efficiency by comparison to the Lightning Imaging Sensor (LIS). Q. J. R. Meteorol. Soc. 2017, 143, 2809-2817. [CrossRef]

30. Lang, T.J. World-Wide Lightning Location Network. 2020. Available online: https://doi.org/10.5067/ Suborbital/CAMP2EX2018/DATA001 (accessed on 1 January 2020).

31. Goodman, S.J.; Blakeslee, R.J.; Koshak, W.J.; Mach, D.; Bailey, J.; Buechler, D.; Carey, L.; Schultz, C.; Bateman, M.; McCaul, E.; et al. The GOES-R Geostationary Lightning Mapper (GLM). Atmos. Res. 2013, 125, 34-49. [CrossRef]

32. Rudlosky, S.; Goodman, S.; Virts, K.S.; Bruning, E.C. Initial Geostationary Lightning Mapper Observations. Geophys. Res. Lett. 2019, 46, 1097-1104. [CrossRef]

33. Blakeslee, R.J.; Lang, T.; Koshak, W.J.; Buechler, D.; Gatlin, P.; Mach, D.M.; Stano, G.T.; Virts, K.S.; Walker, T.D.; Cecil, D.J.; et al. Three Years of the Lightning Imaging Sensor Onboard the International Space Station: Expanded Global Coverage and Enhanced Applications. J. Geophys. Res. Atmos. 2020, 125. [CrossRef]

34. Kummerow, C.; Barnes, W.; Kozu, T.; Shiue, J.; Simpson, J. The Tropical Rainfall Measuring Mission (TRMM) Sensor Package. J. Atmos. Ocean. Technol. 1998, 15, 809-817. [CrossRef]

35. Blakeslee, R.J. Non-Quality Controlled Lightning Imaging Sensor (LIS) on International Space Station (ISS) Science Data; NASA Global Hydrology Resource Center DAAC: Huntsville, AL, USA, 2019. [CrossRef]

36. Mach, D.M.; Christian, H.J.; Blakeslee, R.J.; Boccippio, D.J.; Goodman, S.J.; Boeck, W.L. Performance assessment of the Optical Transient Detector and Lightning Imaging Sensor. J. Geophys. Res. Space Phys. 2007, 112. [CrossRef]

37. Ruf, C.S.; Gleason, S.; McKague, D.S. Assessment of CYGNSS Wind Speed Retrieval Uncertainty. IEEE J. Sel. Top. Appl. Earth Obs. Remote Sens. 2018, 12, 87-97. [CrossRef]

38. Balasubramaniam, R.; Ruf, C.S. Improved Calibration of Cygnss Measurements for Downbursts in the Intertropical Convergence Zone. In Proceedings of the IGARSS 2018-2018 IEEE International Geoscience and Remote Sensing Symposium, Valencia, Spain, 22-27 July 2018; pp. 3987-3990.

39. Balasubramaniam, R.; Ruf, C.S. The Impact of Rain on L1 GNSS-R Radar Scattering Cross-Section. In Proceedings of the IGARSS 2019-2019 IEEE International Geoscience and Remote Sensing Symposium, Yokohama, Japan, 28 July-2 August 2019; pp. 7900-7903. [CrossRef]

40. Asgarimehr, M.; Zavorotny, V.U.; Wickert, J.; Reich, S. Can GNSS Reflectometry Detect Precipitation Over Oceans? Geophys. Res. Lett. 2018, 45, 12585-12592. [CrossRef]

41. Asgarimehr, M.; Wickert, J.; Reich, S. Evaluating Impact of Rain Attenuation on Space-borne GNSS Reflectometry Wind Speeds. Remote Sens. 2019, 11, 1048. [CrossRef] 
42. Priftis, G.; Lang, T.; Chronis, T. Combining ASCAT and NEXRAD Retrieval Analysis to Explore Wind Features of Mesoscale Oceanic Systems. J. Geophys. Res. Atmos. 2018, 123, 10341-10360. [CrossRef]

43. CYGNSS. CYGNSS Level 2 Climate Data Record Version 1.0. Ver. 1.0; PO.DAAC: Pasadena, CA, USA, 2020. Available online: https://doi.org/10.5067/CYGNS-L2C10 (accessed on 22 May 2020).

44. Lang, T.J. Validation of Satellite-Based Wind Observations during PISTON; PISTON Science Team Workshop: Fort Collins, CO, USA, 2019. Available online: https://ntrs.nasa.gov/api/citations/20190032972/downloads/ 20190032972.pdf (accessed on 1 November 2020).

45. Petersen, W.A.; Rutledge, S.A. On the relationship between cloud-to-ground lightning and convective rainfall. J. Geophys. Res. Space Phys. 1998, 103, 14025-14040. [CrossRef]

46. Tapia, A.; Smith, J.A.; Dixon, M. Estimation of Convective Rainfall from Lightning Observations. J. Appl. Meteorol. 1998, 37, 1497-1509. [CrossRef]

47. Bang, S.D.; Zipser, E.J. Differences in size spectra of electrified storms over land and ocean. Geophys. Res. Lett. 2015, 42, 6844-6851. [CrossRef]

48. Bang, S.D.; Zipser, E.J. Seeking reasons for the differences in size spectra of electrified storms over land and ocean. J. Geophys. Res. Atmos. 2016, 121, 9048-9068. [CrossRef]

Publisher's Note: MDPI stays neutral with regard to jurisdictional claims in published maps and institutional affiliations.

(C) 2020 by the author. Licensee MDPI, Basel, Switzerland. This article is an open access article distributed under the terms and conditions of the Creative Commons Attribution (CC BY) license (http://creativecommons.org/licenses/by/4.0/). 